\title{
Non-Hodgkin's lymphoma presenting as a mediastinal mass in a 38-year-old patient with superior vena cava syndrome and extreme fatigue owing to left atrium and right ventricle outflow tract compression: the applicability of strain imaging
}

Sergio Barra, Pedro Gomes, Rui Providência, Joana Trigo

Cardiology Department, Coimbra's Hospital Centre and University, Coimbra, Portugal

Correspondence to Dr Rui Providência, rui_providencia@yahoo.com

\section{DESCRIPTION}

A 38-year-old patient presented with recurrent presyncope, extreme fatigue, facial oedema and weight loss. Physical examination revealed a palpable painless mass in the left supraclavicular region, facial oedema and a mild meso-systolic murmur audible at the right sternal border.

An echocardiogram revealed a mass anterior to the heart compressing cardiac chambers and the aortic root. The compression resulted in a right ventricle outflow tract (RVOT) with less than half its normal anteroposterior diameter and a fusiformly shaped left atrium (LA) of extremely reduced antero-posterior diameter as it was being compressed by the displaced aortic root. Acceleration of blood flow in the RVOT and LA was evident with colour flow Doppler imaging. The lower radial/longitudinal strain of basal-medium segments of anterior and lateral left ventricular walls was documented. A thoracic CT revealed a voluminous mass in the anterior mediastinum and a biopsy diagnosed a non-Hodgkin's lymphoma (diffuse large B cell type). Figures 1-3 illustrate cardiac involvement by the mediastinal mass.

The type of cardiac involvement described herein is extremely unusual, including (a) direct compression of the RVOT with superior vena cava syndrome and presyncopes; (b) indirect compression of LA as the extracardiac mass pushes the aortic root against it, causing extreme fatigue; (c) pericardial effusion and (d) reduced systolic strain of left ventricular wall segments contiguous with the extracardiac mass translating possible infiltration or limitation of contraction by external pressure. Echocardiographic strain imaging may help quantify regional myocardial dysfunction in the case of cardiac compression by a mediastinal tumour.

\section{Learning points}

- Mediastinal masses may present as syncopal or presyncopal episodes due to compression of heart chambers.

- Superior vena cava syndrome is a possible manifestation of a non-Hodgkin's lymphoma presenting as a mediastinal mass.

- Echocardiographic strain imaging has an emerging role for the detection of subclinical cardiac involvement in many disease processes, including lymphomas or other tumours with cardiac involvement.

- This case emphasises the importance of multimodality imaging for a better understanding of the anatomy, degree and extent of cardiac involvement by mediastinal masses.

Competing interests None.

Patient consent Obtained. 


\section{BMJ Case Reports}

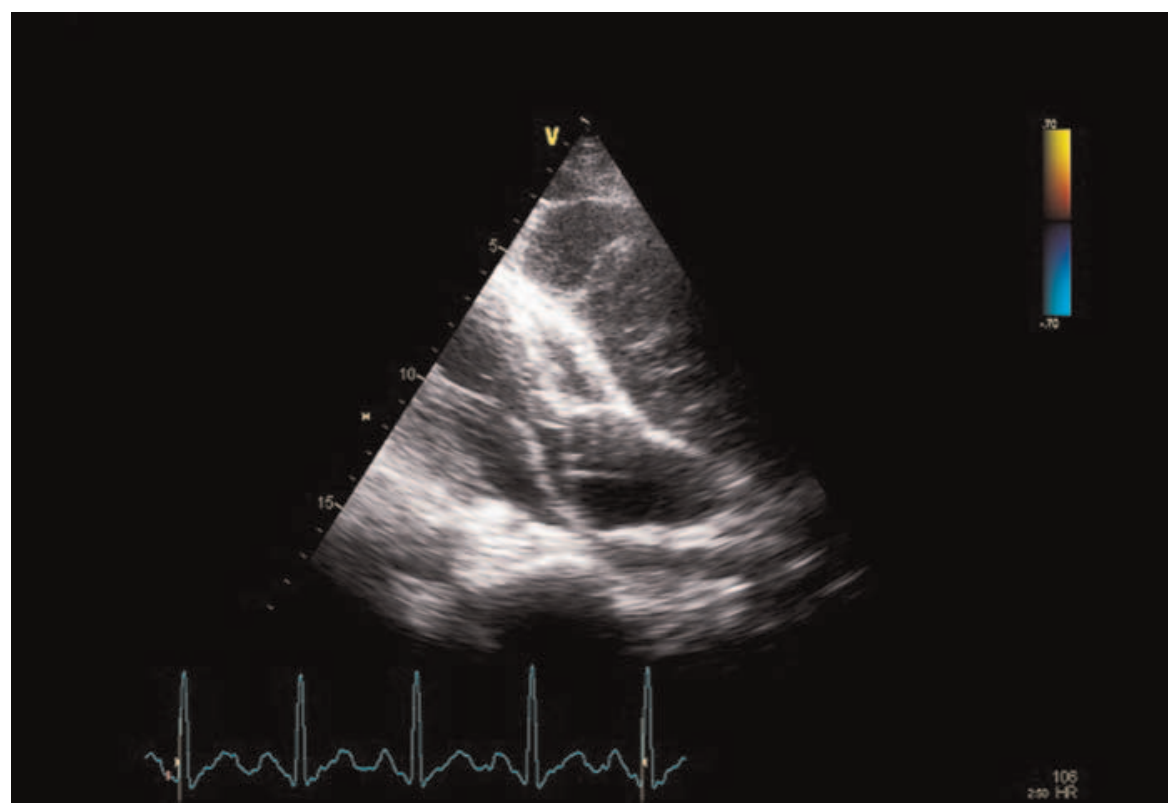

Figure 1 Paraesternal long-axis view revealing direct compression of the right ventricular outflow tract by the extracardiac mass and indirect compression of the left atrium by the displaced aortic root.

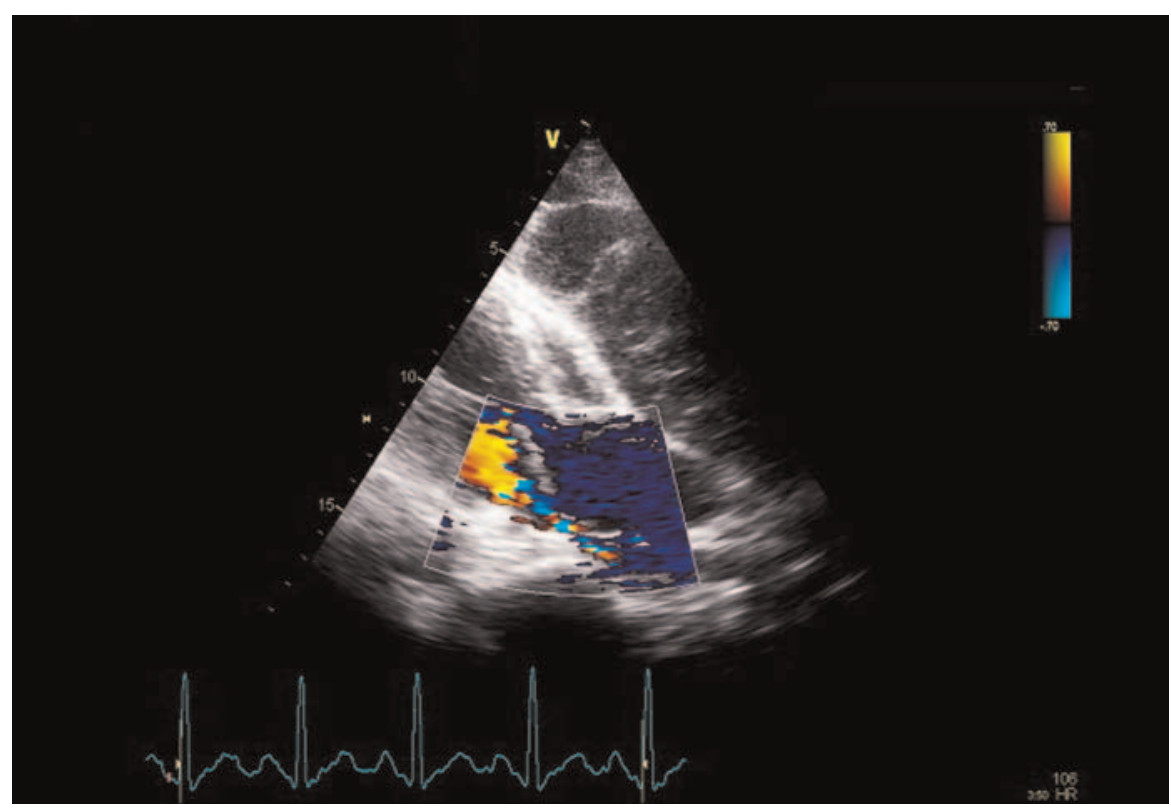

Figure 2 Colour flow Doppler imaging unveiling acceleration of flow in the fusiformly shaped compressed left atrium. 


\section{BMJ Case Reports}

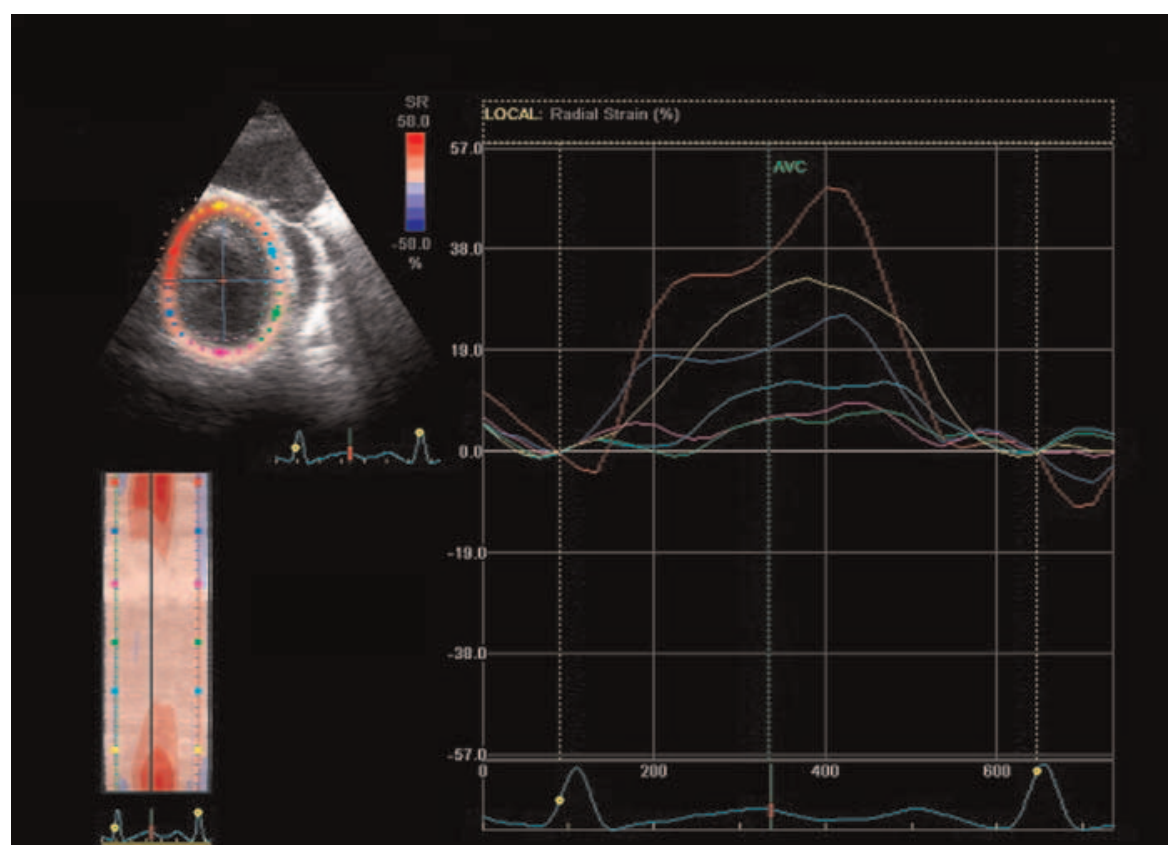

Figure 3 Reduced systolic radial strain rate of anterior and lateral left ventricular walls (light blue and green lines).

This pdf has been created automatically from the final edited text and images.

Copyright 2012 BMJ Publishing Group. All rights reserved. For permission to reuse any of this content visit http://group.bmj.com/group/rights-licensing/permissions.

BMJ Case Report Fellows may re-use this article for personal use and teaching without any further permission.

Please cite this article as follows (you will need to access the article online to obtain the date of publication).

Barra S, Gomes P, Providência R, Trigo J. Non-Hodgkin's lymphoma presenting as a mediastinal mass in a 38-year-old patient with superior vena cava syndrome and extreme fatigue owing to left atrium and right ventricle outflow tract compression: the applicability of strain imaging. BMJ Case Reports 2012;10.1136/ bcr.02.2012.5880, Published XXX

Become a Fellow of BMJ Case Reports today and you can:

- Submit as many cases as you like

- Enjoy fast sympathetic peer review and rapid publication of accepted articles

- Access all the published articles

- Re-use any of the published material for personal use and teaching without further permission

For information on Institutional Fellowships contact consortiasales@bmjgroup.com

Visit casereports.bmj.com for more articles like this and to become a Fellow 